\title{
Enhancement of learned fear with epinephrine
}

\author{
DENNIS K. KAMANO, Galesburg State Research Hospital, \\ Galesburg, Ill. 6140I
}

Given a condition in which there is decay of fear with the passage of time, it was predicted that epinephrine would enhance fear behavior. Rats at 23 days of age received fear conditioning, and 21 days after conditioning, were tested for fear behavior with epinephrine. The epinephrine-treated $S s$ were generally more fearful than the control Ss, indicating further evidence for the fear-enhancing property of epinephrine.

The relationship between epinephrine and fear-mediated behavior (e.g., avoidance behavior) have been explored with conflicting results (Latane \& Schachter, 1962; Leshner \& Stewart, 1966; Stewart \& Brookshire, 1967). One reason for failing to consistently find enhanced fear behavior with epinephrine may be because epinephrine is usually administered to an organism already experiencing fear at or near peak-level. Why introduce epinephrine into an organism that is experiencing peak-level fear?

The degree of fear when epinephrine is introduced may be a critical variable. At reduced level of fear the effect of epinephrine may be more readily apparent. Thus, given a condition in which there is decay of fear with the passage of time, we would expect epinephrine to enhance the fear reaction and affect the fear-related behavior.

Epinephrine is a sympathomimetic agent that produce physiological conditions associated with fear states (Garfield, Gershon, Sletten, Sundland, \& Ballou, 1967; Hawkins, Monroe, Sandifer, \& Vernon, 1960). If the concomitant physiologic reaction to fear could be reproduced by epinephrine, then we would expect it could also affect behavior related to fear. Singer (1963) has reported that epinephrine produced increased indications of fright in rats in a fearful situation.

Campbell \& Campbell (1962) have shown that the retention of fear is dependent upon the retention interval and the age of the rat at the time of fear training. For example, rats conditioned at 23 days of age showed low retention of fear 21 days after fear conditioning. Epinephrine, in this instance, may have a significant effect. Thus, the approach of the present study was to condition 23-day old rats and then test for fear behavior 21 days later using epinephrine, and with the prediction that epinephrine would enhance the learned fear behavior.

\section{SUBJECTS}

The Ss were 26 male Wistar albino rats from the colony maintained at the Galesburg State Research Hospital. They were weaned at 21 days and were housed two per home cage.

\section{APPARATUS}

The apparatus was a modified Mower-Miller shuttle box of unpainted plywood with the bottom $7 \mathrm{in}$. of the front side as Plexiglas window. Each compartment measured $9 \times 9 \times 20.5$ in., and was separated by a vertically sliding panel of unpainted plywood. A $10 \mathrm{~W}$ light bulb was mounted above the "safe" compartment which had a wooden floor 1/4-in. higher than the dark ("fear") compartment with a grid floor of $1 / 8$-in. brass rods set 5/16 in. apart. Shock was delivered through the grid floor by a stimulator that consisted mainly of a power transformer that delivered a $260 \mathrm{~V}$ ac on the secondary, two fixed resistors wired in parallel with a total width of 218,000 resistance ohms, and a variable $250,000-0 h m$ potentiometer calibrated in $\mu \mathrm{A}$ within the range of 25 to $450 \mu \mathrm{A}$.

\section{PROCEDURE}

The procedure used, with some modifications, was similar to that described elsewhere (Campbell \& Campbell. 1962; Campbell \& Jaymes, 1966). The Ss, at age 23 days, were assigned to four groups. With the sliding panel closed, the Ss in Groups $A(N=9)$ and $B(N=9)$ were placed in the fear compartment and given 10 , 3-sec $300 \mu \mathrm{A}$ shocks through the grid floor on a 30-sec variable interval schedule. Then the $S s$ were removed from the fear compartment and placed in the safe (illuminated) compartment for $5 \mathrm{~min}$. At the end of the period the entire procedure was repeated once, and the Ss were returned to their home cages. The Ss in Groups $C(N=4)$ and $D(N=4)$ received a similar treatment but without the shock experience.

Twenty-one days after conditioning, the Ss in Groups $\mathrm{A}$ and $\mathrm{C}$ were injected i.p. with $.10 \mathrm{mg} / \mathrm{kg}$ epinephrine hydrochloride ${ }^{1}$ in normal saline, and Ss in Groups B and D normal saline (placebo), and left in their home cages. The test procedure which was identical for all groups began $15 \mathrm{~min}$ after the injection. With the sliding panel suspended 4 in. above the floor, each $\mathrm{S}$ was always placed in the fear compartment with freedom to move back and forth between the compartments. The test session lasted $30 \mathrm{~min}$ and the time (in seconds) spent in the fear compartment and the number of times $\mathrm{S}$ crossed back and forth were recorded every 6 min. The incidence of urination and defecation were also noted. RESULTS AND DISCUSSION

The control Ss in both Groups $C$ and D spent most of the time in the fear compartment during the test session. The median amount of time (in seconds) spent in the fear compartment for the entire $30-\mathrm{min}$ test session for Groups $\mathrm{C}$ and $\mathrm{D}$ were 1756.5 and 1734.5 , respectively. Since the performance of both groups was essentially similar, they were combined into one control group with a median of 1740 .

The median amount of time (in seconds) spent in the fear compartment for the entire 30-min test session for Groups $A$ and B were 5 (range, 2-139) and 149 (range, 3-819), respectively. Application of individual Mann-Whitney $U$ tests indicated that both Groups A and B differed significantly from the control group $(p<.01)$, and Groups A and B differed significantly from each other $(p<.05)$, indicating that the $S s$ in Group A spent significantly less time in the fear compartment than the Ss in Group B. Group A revealed significantly less crossings between compartments than Group B $(\mathrm{p}<.01)$, but both groups did not differ significantly from each other in urination and defecation.

These results indicated that the Ss in Group B were less fearful than the $\mathrm{Ss}$ in Group $\mathrm{A}$, and were interpreted as supportive evidence that ephinephrine has the effect of enhancing fear behavior. Demonstrating the fear-enhancing property of epinephrine appeared dependent upon the level of fear.

\section{REFERENCES}

CAMPBELL, B. A., \& CAMPBELL, E. H. Retention and extinction of learned fear in infant and adult rats. Journal of Comparative \& Physiological Psychology, 1962, 55, 1-8.

CAMPBELL, B. A., \& JAYNES, J. Reinstatement. Psychological Review, $1966,73,478-480$.

GARFIELD, S. L., GERSHON, S., SLETTEN, I., SUNDLAND, D. M., \& BALLOU, S. Chernically induced anxiety. International Journal of Neuropsychiatry, 1967, 3, 426433.

HAWKINS, D. R., MONROE, J. T., SANDIFER, M. G., \& VERNON, C. R. Psychological and physiological responses to continuous epinephrine infusion: an approach to the study of the affect, anxiety. Psychiatric Research Report, 1960, 12, 40-52.

LATANE, B., \& SCHACHIER, S. Adrenalin and avoidance learning. Journal of Comparative \& Physiological Psychology, 1962, 55, 369-372.

LESHNER, A. I., \& STEWART, C. N. The effect of epinephrine on extinction of an avoidance response. Psychonomic Science, 1966, 5, 89-90. SINGER, J. E. Sympathetic activation, dnsgs, and fear. Journal of Comparative \& Physiological Psychology, 1963, 56, 612-615.

STEWART, C. N., \& BROOKSHIRE, K. H. Shuttie box avoidance learning and epinephrine. Psychonomic Science, 1967, 9, 419-420.

NOTE

1. The epinephrine hydrochloride was supplied by Parke, Davis \& Company. 